\title{
RAPID IN VITRO AND IN VIVO CONVERSION OF HYDROXYMETHYL- NITROFURANTOIN INTO NITROFURANTOIN AS MEASURED BY HPLC
}

\author{
R.H.A. SOREL and H. ROSEBOOM
}

Pharmaceutical Laboratories, University of Utrecht, Cathariinesingel 60, Utrecht (The Netherlands)

(Received October 23rd, 1978)

(Accepted December 13th, 1978)

\section{SUMMARY}

For the first time a method of separation between nitrofurantion and hydroxymethylnitrofurantoin is reported. Until now it has not been possible to separate these two substances because of a rapid degradation of hydroxymethyl-nitrofurantoin into nitrofurantion in, for instance, dimethylformamide and aqueous non-acid solutions.

In vivo studies after administration of a commercially available formulation containing hydroxymethyl-nitrofurantoin, showed only nitrofurantoin to be present in urine. This formulation itself was also partly degraded. These results show that hydroxymethylnitrofurantoin acts as a pro-drug of nitrofurantoin.

\section{INTRODUCTION}

Nitrofurantoin (NF) and hydroxymethyl-nitrofurantoin (HMNF) are both used in the treatment of urinary tract infections. These substances are quickly resorbed from the gastrointestinal tract and are rapidly excreted in the urine. Many authors have differing opinions about the compounds present in the urine after administration of NF and HMNF. Frigerio et al. (1963) assumed a slower biotran sformation for HMNF than for NF, and this should be the reason why more HMNF will be excreted in the urine than NF. English et al. (1966) mention the possibility of a facile in vivo conversion of HMNF into NF but, in contradiction to this, Holmen-Cristensen and Andersen (1967) conclude that HMNF is excreted untransformed. Tromp et al. (1976) suggest that HMNF provides some inactive metabolites, while NF does not.

The main reason for these differing opinions is the fact that until now it has not been possible to separate NF from HMNF.

The colorimetric methods of Buzard et al. (1956) and Conklin and Hollifield (1965, 1966) for the determinaion of NF are non-specific, since HMNF will also be determined (Tromp et al., 1976). The polarographic methods of Jones et al. (1965) and Mason and Sandman (1976) are al-o non-specific due to the nitro-group being present in both substances. In the HPLC method of Roseboom and Koster (in press), the same retention times are found for NF and HMNF. 
The aim of this investigation was to obtain a method of separation for HMNF and NF, and to use this technique to discover in which form HMNF was excreted. In the course of this investigation we found in some cases two peaks for HMNF on HPLC, for which reason we studied the stability of HMNF both as a pure substance and in a commercially available tablet. The cumulative excretion of the two drugs in 4 healthy volunteers was determined and the compounds excreted were identified.

\section{MATERIALS AND METHODS}

\section{Apparatus}

Chromatographic analyses were carried out on a Waters Assoc. (Milford, Mass., U.S.A.) Model 6000A solvent delivery system, a Model U 6K injector and a Model 440 absorbance detector operated at $365 \mathrm{~nm}$. The column was $30 \mathrm{~cm} \times 2 \mathrm{~mm}$ i.d. stainless steel, packed with $\mu$ Bondapak $\mathrm{C}_{18}$ (Waters Assoc.). Mobile phases used were 30 and $40 \% \mathrm{v} / \mathrm{v}$ methanol in water, both containing $0.5 \% \mathrm{v} / \mathrm{v}$ of glacial acetic acid. Different flow-rates are mentioned in the text.

\section{Chemicals}

Dimethylformamide (DMF) was obtained from Merck (Darmstadt, G.F.R.), 2,6-dinitrophenol from Fluka A.G. (Basel, Switzerland), nitrofurantoin from Brocacef (Maarssen, The Netherlands) and hydroxymethylnitrofurantoin was a gift from Inpharzam-Nederland N.V. (Amsterdam, The Netherlands). The two commercial formulations used were Furadantine MC (Norwich) and Urfadyn (Zambon). All other reagents used were of analytical grade.

\section{Methods}

Stability of HMNF in DMF solution and in the chromatographic system

Solutions of HMNF in DMF were injected into the HPLC system $55 \mathrm{~s}$ after preparation (Fig. 1a). The retention time of HMNF on the column was increased by decreasing the flow-rate, while the time HMNF was dissolved in DMF was the same as before the first injection (Fig. 1b). Another injection was done $300 \mathrm{~s}$ after the solution of HMNF in DMF was pr:pared (Fig. 1c). These chromatograms were compared with a chromatogram of NF in DMF (Fig. 1d) and HMNF in a strongly acidic solution $\left(0.5 \% \mathrm{H}_{3} \mathrm{PO}_{4}\right)$ (Fig. le).

\section{Influence of pH on HMNF stability}

Fre solutions of HMNF in $0.1 \mathrm{~N} \mathrm{HCl}$ were mixed with an equal volume of solutions containing different amounts of sodium acetate in $0.1 \mathrm{~N} \mathrm{NaOH}$, pH values being measured after mixing. Each of these solutions was injected several times and peak height ratios were plotted against time. The time at which the ratio was equal to one was considered to be the half-life for the degradation, assuming that this is a pseudo-first-order reaction. The absolute values determined in this viay are not exactly correct, due to the fact that there is a small difference in peak-widths and molar absorptivities of the two compounds.

\section{Identification of degradation products}

In order to identify the product giving the second peak (Fig. 1a-c), an aqueous solu- 
tion of HMNF at $\mathrm{pH} 7$ was allowed to stand for some time until the HMNF peak had disappeared. At that time the solution was extracted with methyl-ethylketcne and the extract evaporated to dryness by means of a rotary evaporator. The mass-spectrum of the remaining crystalline substance was cornpared with those of NF and HMNF. The melting points were also determined.

\section{In vivo studies}

Four healthy volunteers received commercially available preparations of NF ( 1 capsule Furadantine MC of $100 \mathrm{mg}$ ) on day one and HMNF ( 2 tablets Urfadyn, each containing $40 \mathrm{mg}$ ) on day seven. Urine samples of each volunteer were collected in a flask containing $10 \mathrm{ml}$ of $25 \% \mathrm{H}_{3} \mathrm{PO}_{4}$, over a period of $6 \mathrm{~h}$. Urine voided at $\mathrm{t}=0$ was used as the blank. The cumulative excretion of the products was measured after filtering a few millimeters of urine through a $0.2 \mu \mathrm{m}$ filter; $100 \mu \mathrm{l}$ of this filtrate was mixed with $100 \mu \mathrm{l}$ of the internal standard solution (2,6-dinitrophenol in water, $10 \mu \mathrm{g} / 100 \mu \mathrm{l})$ and about $25 \mu \mathrm{l}$ of this mixture was injected into the HPLC system. Standard solutions were made by spiking blank urine. This method is based on the method described by Aufrère et al. (1977), 2,6-dinitrophenol being used as the internal standard instead of furazotidone, which does not separate very well from NF.

\section{Contents of formulations}

The amount of HMNF in Urfadyn was determined by dispersing a tablet in $500 \mathrm{ml}$ of $0.5 \% \mathrm{H}_{3} \mathrm{PO}_{4}$ (in triplicate) and injecting the clear upper layer into the HPLC system. The concentration was calculated by comparing the peak height with those obtained after injection of standard solutions of $\mathrm{HMNF}$ in $0.5 \% \mathrm{H}_{3} \mathrm{PO}_{4}$. The concentration of NF in Furadantine MC was measured by dissolving the contents of a capsule in $50 \mathrm{ml} \mathrm{DMF}$ and diluting this solution to $1000 \mathrm{ml}$ (in triplicate).

\section{RESULTS AND DISCUSSION}

\section{Stability of HMNF in DMF and in the chromatographic system}

The peak height ratios of the two peaks in Fig. 1a and $b$ are equal, while the retention time in Fig. $1 \mathrm{~b}$ is 5 times as long as in Fig. 1a. The only difference was that by decreasing the flow, the number of plates of the column had increased. This clearly shows that degradation is not an on-column effect. Fig. 1c shows that the degradation is almost complete in a few minutes. The increasing peak has the same capacity factor as NF (Fig. 1d), and the decreasing one has the same capacity factor as HMNF (Fig. 1e). HMNF in $0.5 \%$ $\mathrm{H}_{3} \mathrm{PO}_{4}$ was relatively stable $\left(\mathrm{t}_{1 / 2}\right.$ was about 10 days).

\section{Influence of pH on HMNF stability}

Fig. 2 shows $\mathrm{t}_{1 / 2}$ for HMNF degradation plotted against $\mathrm{pH}$. The slope of this line $(-0.939)$ indicates an hydroxyl ion-catalyzed reaction in the $\mathrm{pH}$ range $3.47-4.71$. Extrapolation of this line to $\mathrm{pH} 7.4$ indicates a $t_{1 / 2}$ of a few seconds under physiological conditions. The difference between the slope of this line and unity is probably due to differ- 

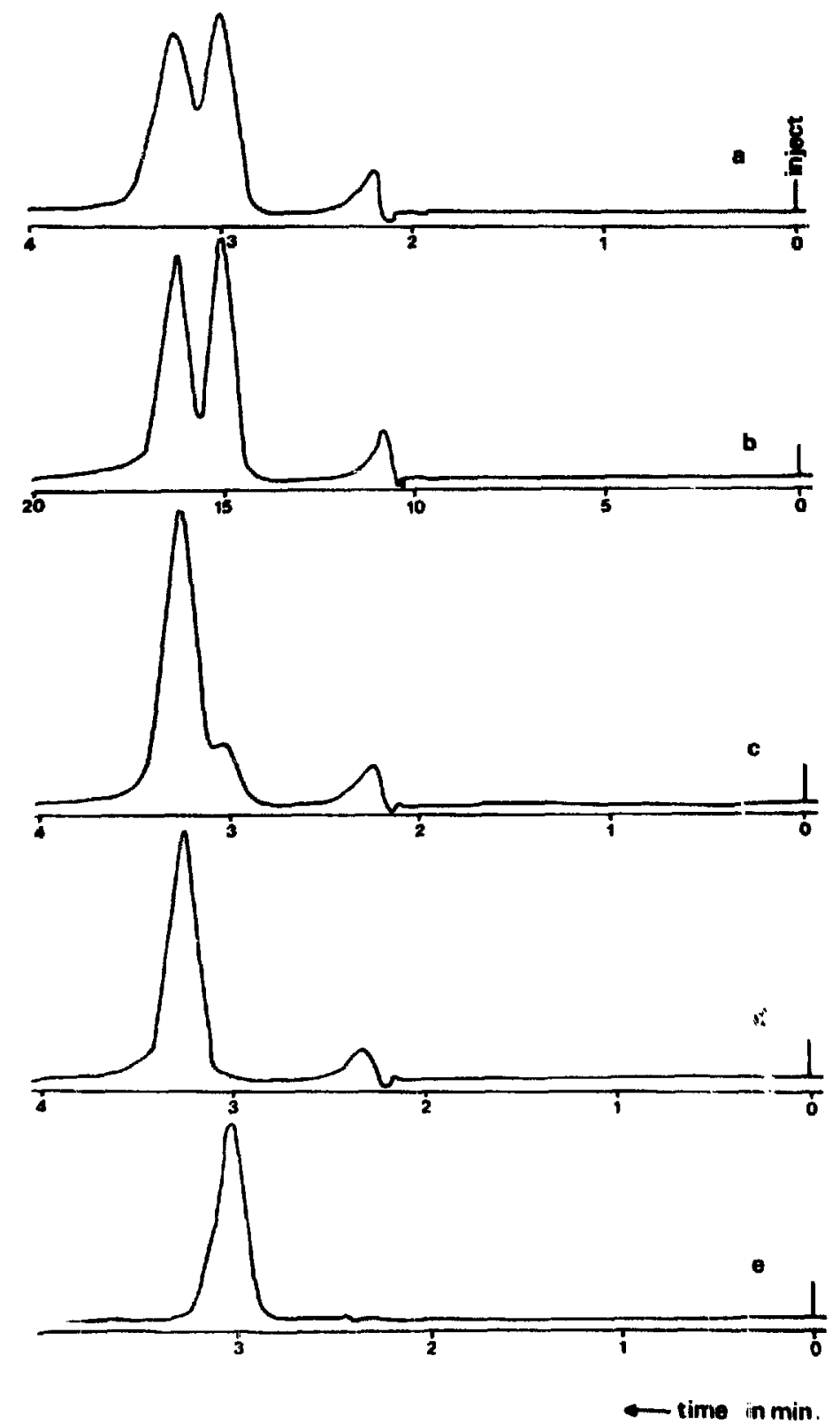

Fig. 1. a: HMNF in DMF, $55 \mathrm{~s}$ after the solution was prepired. Mobile phase, $40 \% \mathrm{v} / \mathrm{v}$ methanol in water with $0.5 \% \mathrm{v} / \mathrm{v}$ glacial acetic acid; flow-rate, $1.5 \mathrm{ml} / \mathrm{min}$; chart-speed, $50 \mathrm{~mm} / \mathrm{min}$. b: as a, flowrate $0.3 \mathrm{ml} / \mathrm{min}$; chart-speed, $10 \mathrm{~mm} / \mathrm{min}$. c: as a, $300 \mathrm{~s}$ after the solution was prepared. $\mathrm{d}: \mathrm{NF}$ in DMF, conditions as in a. e: $\mathrm{HMNF}$ in $0.5 \% \mathrm{H}_{3} \mathrm{PO}_{4}$, conditions as in a.

ences in ionic strength of the buffer solutions and therefore, extrapolation towards $\mathrm{pH} 7.4$ is not very accurate. The $t_{1 / 2}$ of the degradation of HMNF can be determined accurately using a stop-flow technique and isotonic buffer solutions. 


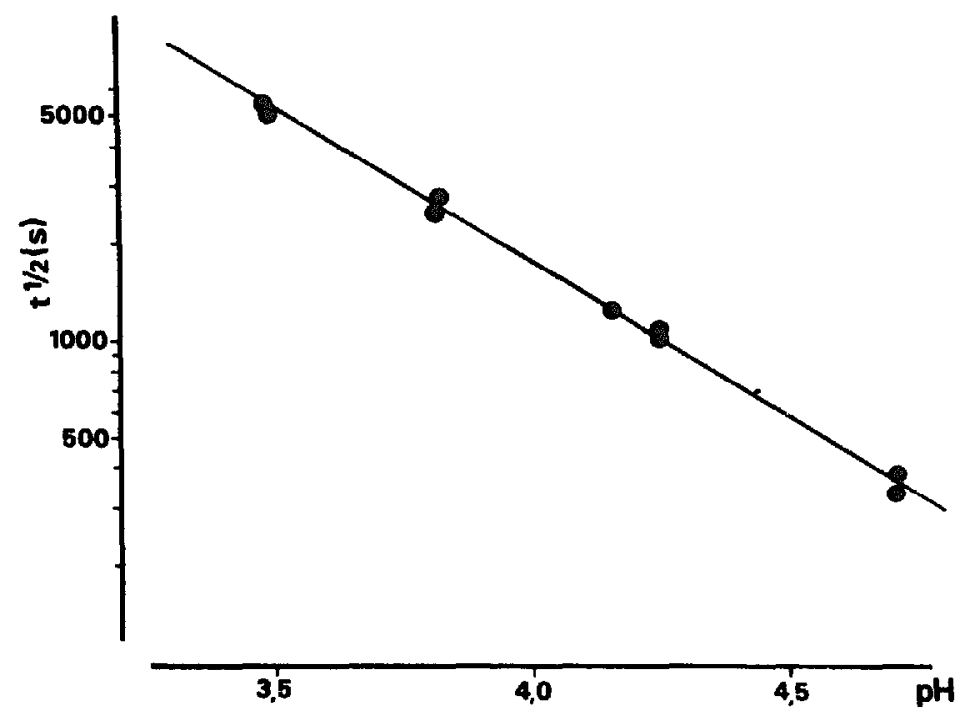

Fig. 2. HMNF half-life plotted versus pH $\left(r^{2}=0.997\right)$.

\section{Identification of degradation products}

Mass-spectra of NF and HMNF showed parent peaks at m/e 238 and m/e 268, respectively. The mass-spectrum of the degradation product was identical with that of NF. Determination of the melting points of NF, the degradation product and the mixture (1/1) of both, also showed the degradation product to be identical with NF. If HMNF degrades into NF, formaldehyde must be another reaction product. This was confirmed by dissolving HMNF in a few drops of $0.1 \mathrm{~N} \mathrm{NaOH}$ in a microtube, covered with a microscope slide with a hanging drop of water. After $15 \mathrm{~min}$ this drop was mixed with two drops of chromotropic acid in concentrated sulfuric acid and gave a violet colour, which is specific for formaldehyde (Feigl, 1960). The same reaction was negative when carried out with NF. Taking into account the information obtained from the chromatographic and mass-spectral analyses, the determination of melting points and the formaldehyde reaction, it is obvious that HMNF is rapidly converted into NF and formaldehyde under the influence of hydroxyl ions. The same reaction takes place in organic solvents such as DMF and pyridine.

\section{In vivo studies}

The results of the cumulative excretion studies are shown in Table 1. We were unable to find any HMNF in the urine after administration of Urfadyn. From the $t_{1 / 2}$ versus $\mathrm{pH}$ plot (Fig. 2) it can be assumed that HMNF is stable under stomach conditions. As soon as it has leit the stomach, either into the intestine or via the stomach wall into the general circulation, it is converted into NF within a few seconds. Differences in cumulative excretion after administration of HMNF or NF are probably due to differences in dissolution rate or resorption from the stomach between the two compounds, and not to differences in metabolism. 
TABLE 1

CUMULATIVE EXCRETION OVER A PERIOD OF 6 HOURS

\begin{tabular}{|c|c|c|c|c|c|}
\hline \multirow[t]{3}{*}{ Volunteer } & \multirow{2}{*}{\multicolumn{2}{|c|}{$\begin{array}{l}\text { Furadantine MC } \\
\text { (100 mg caps.) } \\
\text { excreted NF }\end{array}$}} & \multicolumn{3}{|c|}{ Urfadyn ( $2 \times 40 \mathrm{mg}$ tabl.) } \\
\hline & & & \multirow{2}{*}{ excreted HMNF } & \multicolumn{2}{|c|}{ excreted NF } \\
\hline & mg & $\% a$ & & $\mathrm{mg}$ & $\% \mathbf{b}$ \\
\hline B.f: & 26.9 & 25.9 & $-c$ & 33.5 & 49.8 \\
\hline H.R. & 31.0 & 29.9 & - & 39.2 & 58.2 \\
\hline R.S. & 37.3 & 35.9 & - & 38.0 & 56.5 \\
\hline H.l. & 30.5 & 29.4 & - & 37.4 & 55.6 \\
\hline
\end{tabular}

a Calculated as a percentage of the determined content of the capsules.

b Calculated as a percentage of the amount of NF equivalent to the determined total contents (NF + HMNF) of the tablets.

c Not detectable.
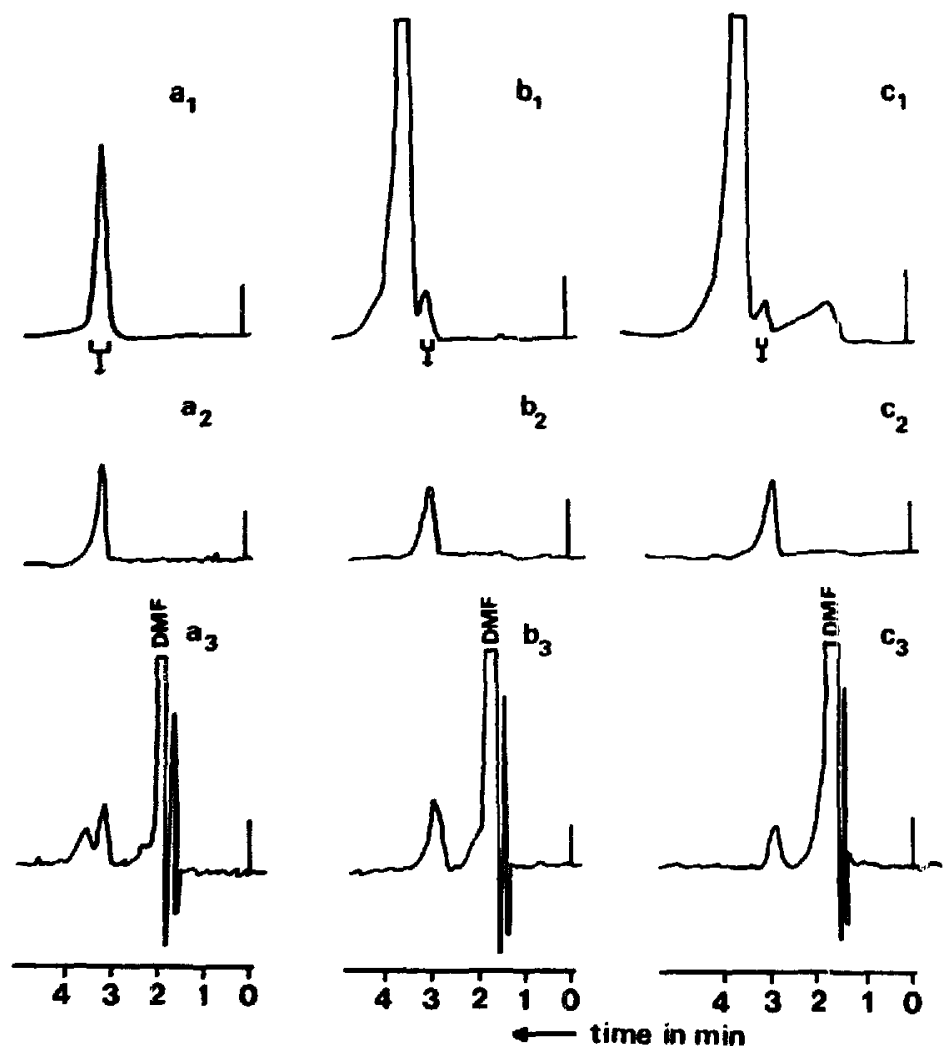

Fig. 3. $a_{1}$ : chromatogram of pure" HMNF in $0.5 \% \mathrm{H}_{3} \mathrm{PO}_{4} . \mathrm{b}_{1}$ : chromatogram of degraded HMNF. $c_{1}$ : chromatogram of urine after administration of Urfadyn. $a_{2}, b_{2}$ and $c_{2}$ : the chromatograms of the control injection, collected as indicated in chromatograms $a_{1}, b_{1}$ and $c_{1} . a_{3}, b_{3}$ and $c_{3}$ : the chromatograms after an equal volume of DMF was added to the fraction $2 \mathrm{~min}$ before injection. Chromatographic conditions: mobile phase, $30 \% \mathrm{v} / \mathrm{v}$ methanol in water with $0.5 \% \mathrm{v} / \mathrm{v}$ glacial acetic acid; flow-rate, $2.0 \mathrm{ml} / \mathrm{min}$. Absorbance: $a_{1}, b_{1}$ and $c_{1}, 0.5 ; a_{2}, b_{2}$ and $c_{2}, 0.02 ; a_{3}, b_{3}$ and $c_{3}, 0.01$. 
After degradation of pure HMNF and Urfadyn, we found a small rest peak with the same capacity factor as HMNF itself. This peak was also present in urine after administration of Urfadyn. To find out whether this was HMNF or an impurity we collected the fractions in which these small peaks were present, re-injectes a few microliters to see if it was free of NF, then added to the rest of the fraction an equal volume of DMF; 2 min later a few microliters were injected into the HPLC system. When this was done with undegraded HMNF the chromatogram showed two peaks (Fig. 3a). With degraded HMNF and urine after administration of Urfadyn, the same single peak remained present (Fig. $3 \mathrm{~b}$ and c). So it can be assumed that an impurity in HMNF causes the small peak in urine samples after administration of Urfadyn.

\section{Contents of formulations}

The analysis of Urfadyn tablets showed that they contained $30.7 \pm 0.5 \mathrm{mg}$ HMNF and $6.4 \pm 0.4 \mathrm{mg} N F$; probably some degradation takes place during the manufacturing process. The Furadantine MC capsules contained $103.8 \pm 0.5 \mathrm{mg} \mathrm{NF}$.

\section{CONCLUSION}

As a consequence of this investigation, where in all chemical and microbiological studies with HMNF only NF was measured, although sometimes in the presence of some formaldehyde, we conclude that in vivo HMNF acts as a pro-drug of NF.

\section{ACKNOWLEDGEMENTS}

The authors wish to thank Dr. J. Renema for recording the mass-spectra and his help with their interpretation.

\section{REFERENCES}

Aufrèı, M.B., Hoener, B. and Vore, M.E., High-performance liquid-chromatographic assay for nitrofurantoin in plasma and urine. Clin. Chem., 23 (1977) 2207-2212.

Buzard, J.A., Vrablic,D.M. and Paul,M.F., Colorimetric determination of nitrofurazone, nitrofurantoin and furazolidone in plasma. Antibiot. Chemother., 6 (1956) 702-707.

Conklin, J.D. and Hollifield, R.D., A new method for the determination of nitrofurantoin in urine. Clin. Chem., 11 (1965) 925-931.

Conklin, J.D. and Hollifield, R.D., A quantitative procedure for the determination of nitrofurantoin in whole blood and plasma. Clin. Chem., 12 (1966) 690-696.

English, A.R., McBride, T.J., Conover, L.H. and Gordon, P.N., 3-Substituted nitrof urantoins as urinarytract anti-infectives. Antimicrob. Agents Chemother., 5 (1966) 434-445.

Feigl, F., Spot Tests in Organic Analysis, 6th edn. Elsevier, Amsterdam, 1960, 349 pp.

Frigerio, G., Grisler, R, and Finulli, M., Ricerche controllate sull'eliminazione urinaria di alcuni preparati nitrofuranici. Minerva Urol., 15 (1963) 120-126.

Holmen-Christensen, H. and Andersen, H.O., A comparative study on the excretion and metabolic degradation of nitrofurantoin and analogues. Acta Pharmacol. Toxicol., 25, Suppl. 4 (1967) 50.

Jones, B.M., Ratcliffe, R.J.M. and Stevens, S.G.E., Comparative assays of some nitrofurans in urine. J. Pharm. Pharmacol., 17 (1965) 52S-55S.

Mason, W.D. and Sandmann, B., Determination of nitrofurantoin in urine by reduction at rotating platinum electrode. J. Pharm. Sci., 65 (1976) 599-601.

Roseboom, H. and Koster, H.A., The determination of nitrofurantoin and some structurally related drugs in biological fluids by high-pressure liquid chromatography. Anal. Chim. Acta, in press.

Tromp, T.F.J., Dankert, J., Remmelts, R.G. en Huizinga, T., De concentratie en antimicrobiële activiteit van nitrofurantoine en hydroxymethylnitrofurantoine in the urine. Ned. T. Geneesk., 120 (1976) $911-918$. 